\title{
EXPERIMENTAL STUDY ON BEHAVIOR OF SIC NANOPOWDER FILLED FLAX AND SISAL FABRIC HYBRID COMPOSITES
}

\author{
SUNIL KUMAR SHETTY ${ }^{1}$, GANESH KALAGI ${ }^{2}$, UDAYA ${ }^{3}$, SHARATH CHANDRA H $\mathbf{S}^{\mathbf{4}}$ \& GAYAK $^{\mathbf{5}}$ \\ ${ }^{1,3,4}$ Faculty of Mechanical Engineering Department, NMAMIT, Nitte, Udupi-574110
}

${ }^{2,5}$ Faculty of Mechanical Engineering Department, Shri MadhwaVadiraja Institute of Technology and Management, Bantakal, Udupi, 574115, Karnataka, India

\begin{abstract}
In the present work, a series of works associated with flax and sisal fabric hybrid composites (FSHC) are fabricated by incorporating SiC (Silicon Carbide) nanopowder as a filler material. The study intends to analyze the result of addition of SiC nanopowder at varied loadings (0, 5 and also 10 weight fraction) on physical, moisture absorption as well as mechanical properties of two different FSHC (15/15 and 20/20 weight fraction) individually. The test results showed that increase in the addition of SiC nanopowder improve the tensile strength, flexural strength as well as resist the moisture absorption of 20/20 wt.\% FSHC, whereas impact strength of both the composition of FSHC increase at 5 wt.\% and further decreases at 10 wt.\% of SiC nanopowder. Fractography analysis was lugged away to check out the nature of fractured sampling.

KEYWORDS: Natural Fiber, SiC Nanopowder, Moisture Absorption Behavior, Mechanical Characterizations and Fractrography
\end{abstract}

Received: Jun 08, 2020; Accepted: Jun 28, 2020; Published: Sep 10, 2020; Paper Id.: IJMPERDJUN20201144

\section{INTRODUCTION}

Fiber material characterizations, composition of fiber and matrix, their orientations, fiber diameter, length of fiber and matrix material characterizations are most important parameters affect the reinforced polymer composites (FRPC) features [1]. Chemicals such as cellulose, lignin, waxes and pectin are contains of natural fibers [2]. Researchers studied the behavior and characterizations of some of natural fibers such bamboo, coir, hemp and jute [3-4]. Saheb et al. [5] reported that, the various factors like fiber chemical treatment, matrix material and fibermatrix bonding are influence the characterizations of natural fiber reinforced composite.

The flax can be used to generate printed banknotes in specifically excellent quality paper industry and utilized for making paper for cigarettes as well as tea bags [6]. Flax plants are normally gathered in European, the location where the typical temperature is typically below $30^{\circ} \mathrm{C}$ [7]. Pavithran et al. [8] explored the effect of natural fibers on impact strength of polyester based natural fiber strengthened composites. The writer had actually reported that sisal fiber reinforced compounds have more crack resistance than pineapple fiber composites.

Khan et al. [9], examined the woven hemp textile enhanced polymer composites, whose studies revealed that fiber strings have interlacing framework of warp and weft. In the tensile loads, these curve fibers trigger higher stress on the procession and have a tendency to go out. This caused produce high stress and anxieties within the matrix. This resulted in higher strength of the woven material than that of the strength of non-woven. The mechanical properties were significantly improved at a volume fraction of fiber 0.40 . 
Using alternative layers of glass fiber and carbon fiber, high tensile strength was achieved and created a good adhesive bond between glass-carbon fabric layers with matrix.[10]. Filler products are used to minimize cost of products, to boost the mechanical, moisture absorption resistance and also put on wear properties of composites. Incorporation of solid filler phase can boost the physical and also mechanical properties of composites. the result of red mud filler powder on bamboo fiber enhanced compounds and glass fiber reinforced composites (GFRC) [11]. Biswas et al [12] examined the result of red mud and also copper slag fillers on the mechanical and physical properties of bamboo fiber strengthened polymer composites has actually been studied as well as the mix of fillers has been shown to boost the tensile toughness of the composition as well as enhance the physical and mechanical characterizations of copper slag compared to red mud composites. Gaurav agarval et al. [13] examined the thermo-mechanical behavior of SiC filled up sliced glass fiber enhanced compounds and it was located that the $\mathrm{SiC}$ has revealed to raise the physical and mechanical properties. However, including even more $\mathrm{SiC}$ material cause deterioration in energy absorption ability of product as well as additionally including as well much $\mathrm{SiC}$ in composite resulted in elastic behavior of composite. Amar Patnaik et al. [14] examined the impact of various of filler product like $\mathrm{SiC}, \mathrm{Al}_{2} \mathrm{O}_{3}$, and also ache bark dust on abrasion wear and also mechanical properties of glass fiber epoxy compounds, the results revealed that decrease in the tensile strength in all particulate filled up composites except these particulate fillers b composites. Satapathy et al. [15] also strengthened the properties of jute-epoxy composites by reinforcing it with SiC. Biswas et al. [16] studied the effect of various ceramic fillers includes $\mathrm{SiC}, \mathrm{Al}_{2} \mathrm{O}_{3}$ and commercial wastes copper slag and red mud on mechanical properties of bamboo fibers reinforced hybrid composites and results showed decrease in tensile strength in all cases where as void content decreases by integrating $\mathrm{SiC}$ and red mud fillers into bamboo fiber reinforced and glass fiber reinforced composites. Kalagi et.al. [[17]] studied the effect of glass fiber on flax/sisal composites and results showed that introduction of glass fiber improved the mechanical properties of flax/sisal composites materials significantly.

The purpose of this study is to analyze the effect of SiCnanopowder at different weight percentage $(0,5,10 \mathrm{wt} . \%)$ on density, moisture absorption, mechanical and fractrography properties of two different hybrid composites made up of alternative plies of flax and sisal fabric (15/15 and 20/20 wt \%).

\section{METHODOLOGY}

\section{Materials}

In the present work, natural fibers such as flax and sisal are used in the polymer LY 556 to manufacture a number of hybrid composite specimens Also, $\mathrm{SiC}$ nanopowder synthesized by aerosol-assisted chemical vapor deposition method to a size less than $80 \mathrm{~nm}$ and was used as filler material (shown in figure1.d). The density and melting temperature of SiC Nanopowder is $3.1 \mathrm{gm} / \mathrm{cc}$ and $2730^{\circ} \mathrm{C}$ respectively. Pictorial views of flax plain woven fiber, sisal plain woven fiber and $\mathrm{SiC}$ nanopowder used for fabrication of hybrid composite for this study are given in figure 1.

\section{Composite Preparation}

For the purpose of experimentation, basically two sets of hybrid composite specimens were prepared using hand layup process. In the first set of specimen's flax/sisal reinforcements are used along with the epoxy resin as matrix material as shown in Figure.1. The variations in the compositions are as indicated in Table.1. In the second set of specimens the hybrid composites are prepared with introduction of $\mathrm{SiC}$ nanopowder in addition to the first set of hybrid composites. The variation in the compositions of second set of hybrid composites is also indicated in the Table.1. 
The wax is used to ensure easy demolding of the prepared specimens from the mold after curing. Soon after the preparation of the mold, it is subjected to a uniform load of $50 \mathrm{~kg}$ for duration of 24 hours to ensure homogeneous structure. Then the demolded specimens were dried at room temperature for the next 24 hours. The final specimens were machined as per the requirement in accordance with ASTM standards

(a)

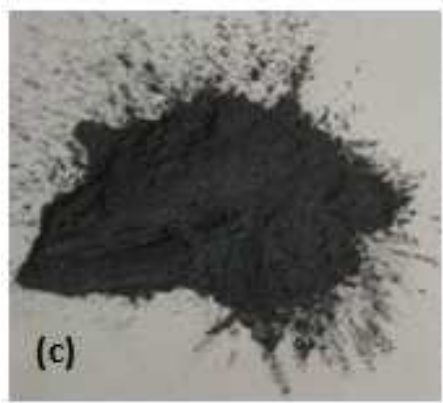

(b)

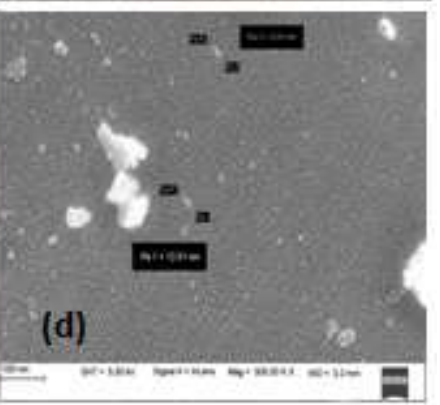

Figure 1: Photographs of (a) Flax Fabric (b) Sisal Fabric (c) SiC nanopowder (d) SEM image SiC nanopowder.

Table 1: The Designation, Stacking Sequences and Detailed Composition of the Hybrid Composites

\begin{tabular}{|l|c|l|}
\hline Specimen Designation & Stacking Sequence & \multicolumn{1}{c|}{ Composition } \\
\hline $15 / 15$ wt.\% FSHC (A) & FSFSFS & Epoxy (70 wt.\%) + Flax (15 wt.\%) + Sisal (15 wt.\%) \\
\hline 20/20 wt.\% FSHC (B) & FSFSFSFS & Epoxy (60 wt.\%) + Flax (20 wt.\%) + Sisal (20 wt.\%) \\
\hline $\begin{array}{l}\text { 5 wt.\% SiC-15/15 wt.\% } \\
\text { FSHC (C) }\end{array}$ & FSFSFS+SiC & $\begin{array}{l}\text { Epoxy (65 wt.\%) + Flax (15 wt.\%) + Sisal (15 wt.\%) + SiC } \\
\text { Nanopowder (5 wt.\%) }\end{array}$ \\
\hline $\begin{array}{l}10 \mathrm{wt} \% \mathrm{SiC}-15 / 15 \\
\text { wt.\% FSHC (D) }\end{array}$ & FSFSFS+SiC & $\begin{array}{l}\text { Epoxy (60 wt.\%) + Flax (15 wt.\%) + Sisal (15 wt.\%) + SiC } \\
\text { Nanopowder (10 wt.\%) }\end{array}$ \\
\hline $\begin{array}{l}\text { 5 wt.\% SiC-20/20 wt.\% } \\
\text { FSHC (E) }\end{array}$ & FSFSFSFS+SiC & $\begin{array}{l}\text { Epoxy (55 wt.\%) + Flax (20 wt.\%) + Sisal (20 wt.\%) + SiC } \\
\text { Nanopowder (5 wt.\%) }\end{array}$ \\
\hline $\begin{array}{l}10 \mathrm{wt} \% \mathrm{SiC}-20 / 20 \\
\text { wt.\% FSHC (F) }\end{array}$ & FSFSFSFS+SiC & $\begin{array}{l}\text { Epoxy (50 wt.\%) + Flax (20 wt.\%) + Sisal (20 wt.\%) + SiC } \\
\text { Nanopowder (10 wt.\%) }\end{array}$ \\
\hline
\end{tabular}

\section{Characterizations}

\section{Density}

The physical attributes of composite materials are as important as their mechanical properties in assessing suitability of these materials for a specific application. Density plays a key role for designing an engineering component or deciding the application of a material particularly where weight is a significant factor. Thus, it is crucial to determine the density of the composites. The actual density of material is determined as per ASTM D792.

The specific gravity of material is given by:

$$
\mathrm{S}_{\mathrm{ct}}=\frac{w_{\mathrm{s}}}{w_{0}+\left(w_{z}-w_{\mathrm{b}}\right)}
$$


Where, $\mathrm{S}_{\mathrm{ct}}$ is specific gravity of the composite, $\mathrm{W}_{\mathrm{o}}$ is the weight of the sample in air, $\mathrm{W}_{\mathrm{a}}$ is the weight of the pychnometer and water, $\mathrm{W}_{\mathrm{b}}$ is the weight of the water, specimen and pychnometer.

Actual density of material is given by,

$$
\mathrm{Pac}_{\mathrm{at}}=\mathrm{s}_{\mathrm{ct}} \times \mathrm{P}_{\mathrm{w}}
$$

Where, $P_{w}$ is the actual density of composite material, $S_{\mathrm{ct}}$ is the specific gravity and $P_{W}$ is the density of water.

The theoretical density $\left(\rho_{c t}\right)$ of composites in terms of weight fraction is obtained using the relation.

$$
p_{\mathrm{ct}}=\frac{1}{\left(\mathrm{w}_{\mathrm{f}} / \mathrm{pr}_{\mathrm{f}}\right)+\left(\mathrm{w}_{\mathrm{m} / \mathrm{p}_{\mathrm{m}}}\right)}
$$

Where, $w$ and $\rho$ designates the weight fraction and density respectively. The suffix $f, m$ and ct represent the fiber, matrix and the composite materials, respectively. Composites under this investigation consist of three different components namely matrix, fiber and nano filler material.

The expression for the density of hybrid composites has been modified as;

$$
P_{\mathrm{ct}}=\frac{1}{\left(\mathrm{w}_{\mathrm{f} / \mathrm{pl}}\right)+\left(\mathrm{w}_{\mathrm{m} / \mathrm{p}_{\mathrm{m}}}\right)+\left(\mathrm{w}_{\left.\mathrm{n} / \mathrm{p}_{\mathrm{n}}\right)}\right.}
$$

Where, suffix n represents $\mathrm{SiC}$ nanopowder

The actual density $\left(\rho_{a c}\right)$ of the composites is determined by simple water immersion technique. By using the theoretical and also experimental density of composites, the volume fraction of voids $\left(\mathrm{V}_{\mathrm{v}}\right)$ in the composites is determined as per ASTM D-2734-70 standard guidelines. "A void is a porous that remains unoccupied in a composite material. A void is usually the outcome of an imperfection from the processing of the material and is generally deemed undesirable". Because, a void is a non-uniformity in a composite material, it can affect the mechanical properties as well as life of the material. Voids can act as crack nucleation sites as well as they allow moisture to penetrate the composite and contribute to anisotropy of the composite. "For aerospace applications, a void content of approximately $1 \%$ is appropriate for performance while other grades of composites can have between 3\%-5\% void content". The volume fraction of void $\left(\mathrm{V}_{\mathrm{v}}\right)$ in the composites is determined using the following equation:

$$
\mathrm{v}_{\mathrm{v}}=\frac{p_{\mathrm{xt}}-p_{\mathrm{xc}}}{p_{\mathrm{xt}}}
$$

\section{Moisture Absorption}

In this research, ASTM D5229 is the standard used to measure the moisture absorption of composites materials. This standard offers procedures to produce data that can effectively be utilized to find the moisture absorption characteristics of polymer reinforced composites. The specimens were first washed with acetone to remove external pollutant particles and dried up in an oven at $35^{\circ} \mathrm{C}$ and then cooled out to room temperature in a desiccator. Afterwards, the weights of the completely dry samples were determined individually by using digital scale. The test samples or specimens were then submerged right in pure water at room temperature.

The moisture content was calculated using the equation.

$$
\text { Weight gain }(\%)=\frac{M_{t}-M_{s}}{M_{\odot}} \times 100
$$


Where, $\mathbf{M}_{t}$ denotes the mass of the specimen at a specified time, whereas $\mathbf{M}_{\mathrm{o}}$ represents the initial mass of the specimen.

\section{Tensile Strength}

Tensile test determines the tensile strength and Young's modulus of the material. Tensile strength is the optimal value a material can endure. The tensile test is generally performed on flat specimens. The ASTM D3039 examination approach is used to establish the tensile properties of fiber reinforced polymer composites. In the present work, this test is performed in the Universal Testing Machine (UTM) Zwick/Roell Z020 of capacity up to $2500 \mathrm{kN}$ at a crosshead speed of $2 \mathrm{~mm} / \mathrm{min}$ and readings were carefully noted down to determine the tensile strength of composite samples.

\section{Flexural Strength}

The flexural strength of a composite is the maximum stress which it can withstand during bending before reaching the breaking point. The three-point bend test is carried out on all the composite samples in Zwick/Roell Z020 UTM up to 2500 $\mathrm{kN}$ at a speed of $2 \mathrm{~mm} / \mathrm{min}$. Flexural test is carried out accordance with ASTM D790-03.

\section{Impact Strength}

Impact test determines the amount of energy absorbed by the material during fracture. This absorbed energy is measure of toughness. This test can represent the brittle and ductility behavior of material. In the present work, Izod impact tests are conducted as per ASTM D256 using an impact tester Zwick/Roell HIT 50P. The standard specimen prepared as per ASTM standard D 256, is impacted by a pendulum with a velocity of $3.458 \mathrm{~m} / \mathrm{s}$ when dropped from a height of $610 \mathrm{~mm}$.

\section{Field Emission Scanning Electron Microscopy}

Microstructures of the fractured hybrid composite samples were examined using a Field Emission Scanning Electron Microscope (FE-SEM). Before taking micrographs, a thin film of gold was coated onto the surface of the samples in vacuum chamber in order to enhance the conductivity of the samples.

\section{RESULTS \& DISCUSSION}

\section{Density and Void Fraction}

Table. 2 presents theoretical and actual densities along with the corresponding volume fraction of voids in composites. It is observed that, the theoretically obtained densities are marginally higher than the experimentally measured values. This difference between theoretical density and actual density of composite is a measure of voids and pores present in the composites.

The volume fraction of voids increase with increase in incorporation of SiC nanopowder into both the composition of (15/15 and 20/20 wt.\%) FSHC. This is due to the incompatibility of SiC nanopowder including epoxy resin material which results in agglomeration of $\mathrm{SiC}$ nanopowder. The volume fraction of voids increases with increase in flax/sisal fabric loading from $15 / 15$ wt. $\%$ to $20 / 20$ wt. $\%$ and this is attributed to increase in flax/sisal fabric weight percentage weaker the adhesion between matrix and reinforcement. 
Table 2: Density and Void Fractions of Composite Specimens

\begin{tabular}{|c|c|c|c|}
\hline Specimen & Theoretical Density $\left(\mathbf{g m} / \mathbf{c m}^{\mathbf{3}}\right)$ & Actual Density $\left(\mathbf{g m} / \mathbf{c m}^{\mathbf{3}}\right)$ & Volume Fraction of voids (\%) \\
\hline A & 1.21 & 1.2 & 0.83 \\
\hline B & 1.23 & 1.11 & 9.76 \\
\hline C & 1.25 & 1.2 & 4.00 \\
\hline D & 1.29 & 1.27 & 1.55 \\
\hline E & 1.27 & 1.21 & 4.72 \\
\hline F & 1.32 & 1.22 & 7.58 \\
\hline
\end{tabular}

\section{Moisture Absorption}

Moisture absorption curves for FSHC incorporated with and without SiC nanopowder fiber are shown in figure 2.Itis observed that $10 \mathrm{wt} . \%$ of SiC nanopowder filled up FSHC enhance the moisture absorption resistance for first couple of days as well as there after it lowers. Nevertheless, consolidation of 0 wt.\% and $5 \mathrm{wt}$ \% SiC nanopowder into FSHC showed better resistance to moisture absorption than $10 \mathrm{wt}$ \% of SiCnanopowder filled FSHC. This is attributed to large number of pores and voids present in the $10 \mathrm{wt} . \%$ of $\mathrm{SiC}$ nanopowder filled FSHC Moisture absorption is more in 0 wt.\% $\mathrm{SiC}$ nanopowder filled 20/20 wt.\% of FSHC. It is further noticed that as SiC content increases in the FSHC, resistance to moisture absorption decreases. This is attributed to two reasons, one is incompatibility of SiC nanopowder with resin matrix and other one is hydrophilic nature of flax and sisal fibers.

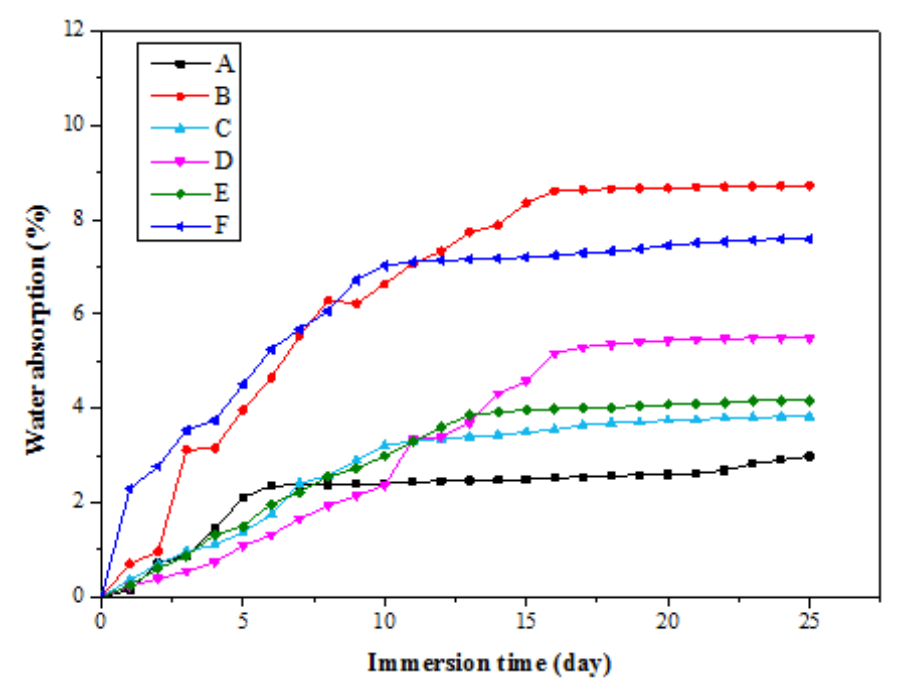

Figure 2: Water Absorption Curves of Hybrid Composites.

\section{Mechanical Properties}

\section{Tensile Strength Properties}

Unfilled flax/sisal (20/20 wt.\%) hybrid composite has a strength of $30.7 \mathrm{MPa}$ in tension and this value increases to 33.1 $\mathrm{MPa}$ and 33.2 $\mathrm{MPa}$ with addition of $5 \mathrm{wt} . \%$ and $10 \mathrm{wt} \%$ of $\mathrm{SiC}$ nanopowder respectively.

Figure 3 presents the tensile strength of composite material decreased with increase in SiC nanopowder content into flax/sisal (15/15 wt.\%) hybrid composites. Whereas these properties are increased with increase in SiC nanopowder content into flax/sisal (20/20 wt.\%) hybrid composites. This is attributed to the fact that the amount of resin is more in 15/15 wt.\% and $\mathrm{SiC}$ nanopowder is incompatible with resin material resulted in agglomeration of SiC nanopowder which caused the disturbance of matrix continuity. This resulted in poor load transfer between fibers leading to failure of material. 
Figure. 4 shows stress-strain curve SiC nanopowder filled flax/sisal hybrid composites. It indicates that the yield strength of the hybrid composite increases with increase in SiC nanopowder content into flax/sisal (20/20 wt.\%) hybrid composites, whereas addition of $\mathrm{SiC}$ nanopowder into flax/sisal (15/15 wt.\%) hybrid composites resulted in a decline in modulus of hybrid composites. This is attributed to $\mathrm{SiC}$ nanopowder has poor interaction with resin matrix, resulted in poor adhesion bonding between fibers and matrix material. Therefore, show lower tensile properties in SiC nanopowder filled flax/sisal (15/15 wt.\%) hybrid composites compared to SiC nanopowder filled flax/sisal (20/20 wt.\%) hybrid composites.

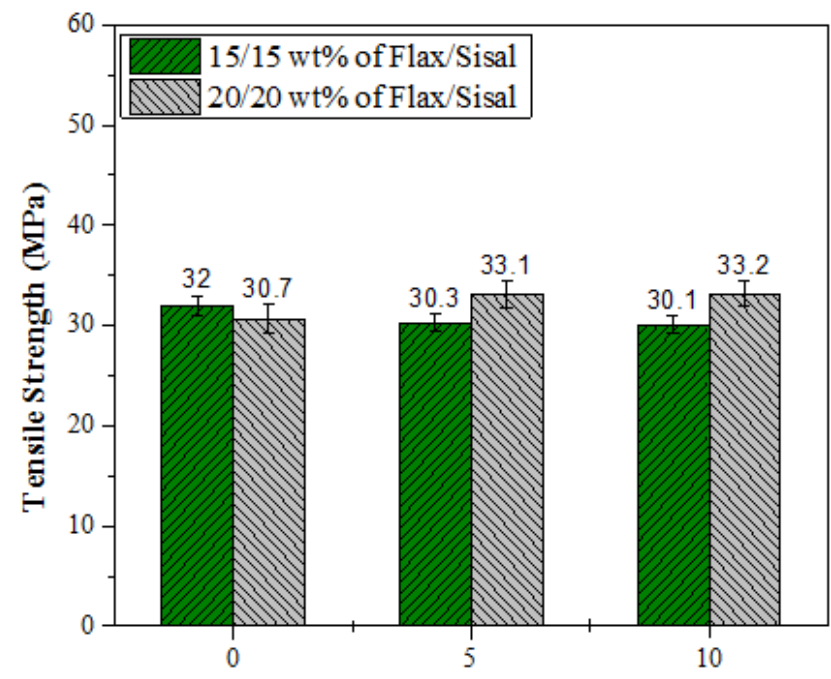

SiC Nano Powder Content (wt \%)

Figure 3: Effect of SiC Nanopowder on Tensile Properties of FSHC.

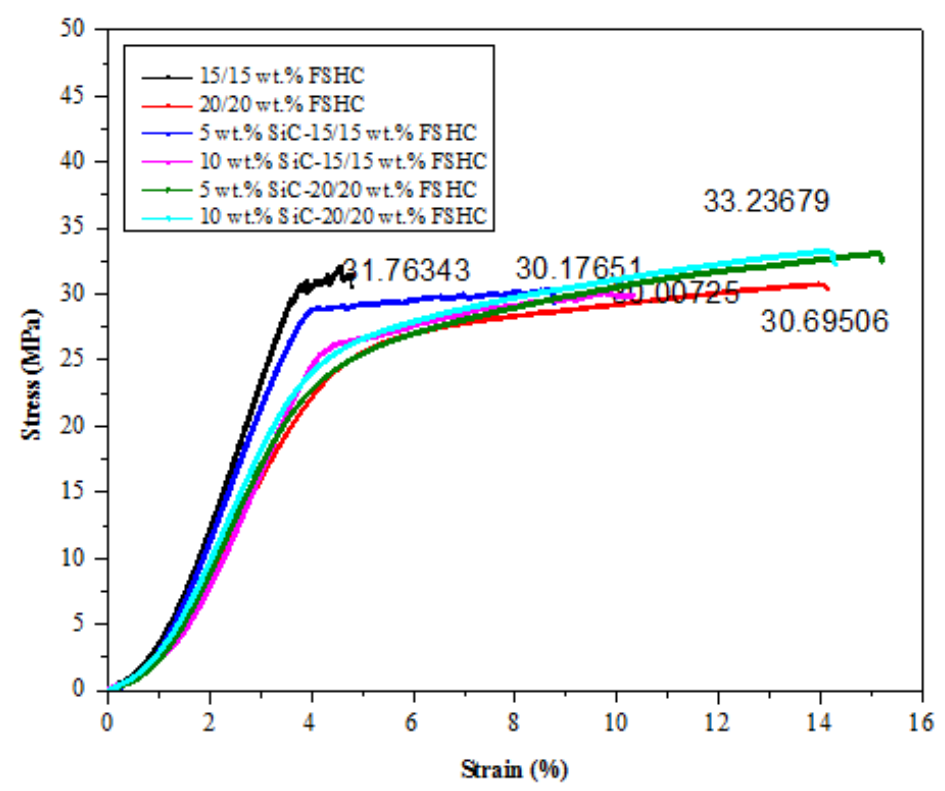

Figure 4: Stress vs Strain Curve for SiC Nanopowder Filled Flax/Sisal Hybrid Composites.

\section{Flexural Strength Properties}

Figure. 5 presents the flexural strength decreases with increasing in SiC nanopowder content into flax/sisal (15/15 wt.\%) hybrid composites. Whereas these properties are improved possibly with increasing in SiC nanopowder content into flax/sisal (20/20 wt.\%) hybrid composites. 


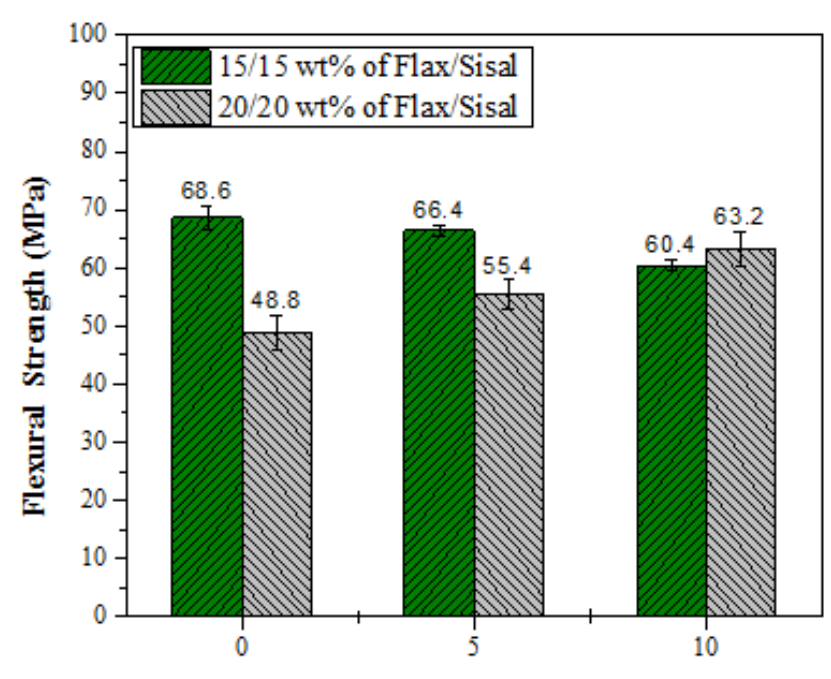

SiC Nano powder Content (wt \%)

Figure 5: Effect of SiC Nanopowder on Flexural Properties of FSHC.

\section{Impact Strength Properties}

The impact strength of fiber reinforced composites depends on many factors including the nature of the constituent, fiber/matrix interface and test conditions. Effect of SiCnanopowder on impact strength of different composition of flax/sisal hybrid composites are presented in figure.6. The impact energy of hybrid composites increases with increase in flax/sisal fabric loading from 15/15 wt.\% to 20/20 wt.\% without incorporation of SiCnanopowder. Impact strength of flax/sisal (15/15 wt.\%) hybrid composites significantly improve with increase in SiCnanopowder content from 0 to 5 wt.\% and further addition of SiCnanopowder leads to decline in impact energy absorbed. In flax/sisal (20/20 wt.\%) hybrid composites, impact energy decreases as SiCnanopowder content increases from 0 to $5 \mathrm{wt} \%$ and further addition of SiCnanopowder from 5 to $10 \mathrm{wt}$.\% leads to increase in impact strength of hybrid composite. However, maximum impact strength energy is found in $10 \mathrm{wt} . \%$ SiCnanopowder incorporated with flax/sisal (20/20 wt.\%) hybrid composite. Impact strength of all flax/sisal (20/20 wt.\%) hybrid composites are improved significantly, whereas all flax/sisal (15/15 wt.\%) hybrid composites showed declining values of impact energy.

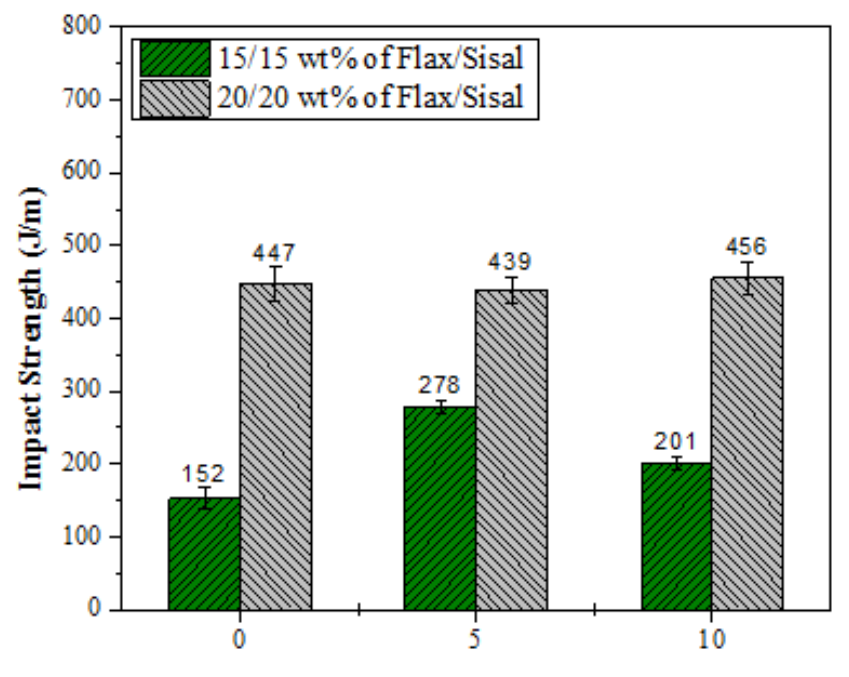

SiC Nano powder Content (wt \%)

Figure 6: Effect of SiC Nanopowder on Impact Properties of FSHC. 


\section{Fractrography Study Of SiC Nanopowder Filled Flax/Sisal Hybrid Composites}

Figure. 7 (a) and figure 7 (b) shows SEM micrograph of fractured unfilled flax/sisal hybrid composite specimen after tensile test. As seen in figure 7 (a) unfilled flax/sisal hybrid composites have strong adhesion bonding between fiber and matrix. Figure 7 (b) shows the SEM image of fractured SiC nanopowder filled flax/sisal hybrid composites after tensile test, which indicates poor adhesion and agglomeration of filler material resulted in pores in composite. From this study, it is clear that the presence of pores, inadequate adhesions between the fibers and matrix and agglomeration of filler material are the major causes for the laminate failure.
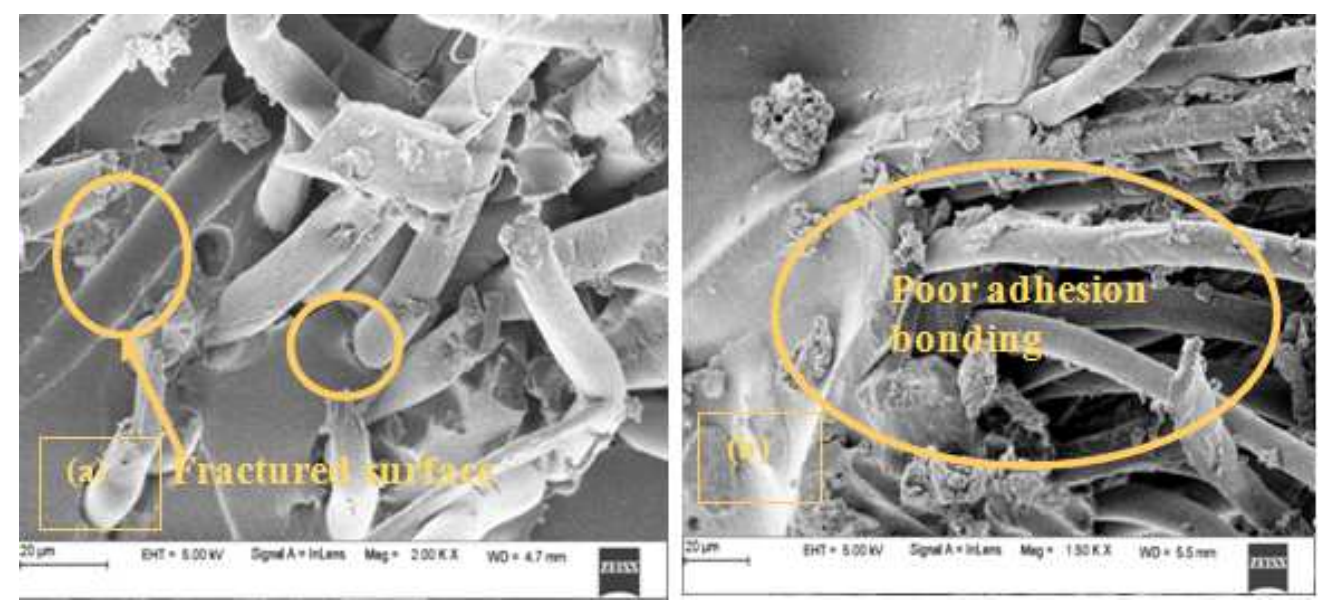

Figure 7: SEM Micrograph of Fractured Surfaces of (a) Unfilled Flax/Sisal Hybrid Composite (b) SiC Nanopowder Filled Flax/Sisal Hybrid Composite.

\section{CONCLUSIONS}

Effect of SiC Nanopowder content on characterizations of two different compositions of FSHC have been experimentally studied. These composites are suitable for low load applications and small wind turbine blades. Conclusions of this study are as follows:

- Incorporation of SiC nanopowder into 20/20 wt\% FSHC increases mechanical and moisture absorption resistance characteristics, whereas incorporation of SiC nanopowder into 15/15 wt\% FSHC decreases the mechanical and moisture absorption resistance characteristics of composites.

- Maximum tensile strength and young's modules values are found in 20/20 wt\% FSHC incorporated with SiC nanopowder, whereas maximum flexural strength is found in $0 \mathrm{wt} \% \mathrm{SiC}$ nanopowder filled 20/20 wt $\%$ FSHC.

- Addition of $\mathrm{SiC}$ nanopowder influences the density of flax/sisal hybrid composites, as SiC nanopowder content increase density of composite also increased.

- It is also revealed that increase in $\mathrm{SiC}$ nanopowder in 20/20 wt\% FSHC resulted in uneven impact strength of composites. Addition of $5 \mathrm{wt} \% \mathrm{SiC}$ nanopowder showed maximum impact strength among 15/15 wt\% FSHC.

- The factors such as weak bonding, agglomeration of SiC nanopowder and presence of voids are affects the density, mechanical properties and moisture absorption and this is analyzed by Fractrography study using SEM. 


\section{REFERENCES}

1. S. Mishra, A. K. Mohanty, L. T. Drzal, M. Misra, and S. Parija, "Studies on mechanical performance of biofibre / glass reinforced polyester hybrid composites," vol. 63, pp. 1377-1385, 2003.

2. M. M. Kabir, H. Wang, K. T. Lau, F. Cardona, and T. Aravinthan, "Mechanical properties of chemically-treated hemp fibre reinforced sandwich composites,” Compos. Part B Eng., vol. 43, no. 2, pp. 159-169, 2012.

3. M. Idicula, S. K. Malhotra, K. Joseph, and S. Thomas, "SCIENCE AND Dynamic mechanical analysis of randomly oriented intimately mixed short banana / sisal hybrid fibre reinforced polyester composites," vol. 65, pp. 1077-1087, 2005.

4. Kumar, T. Vijaya, and K. V. Ramana."Effect of Ball Milling on microstructural parameters of nanostructured MoO3-CuOV2O5 composite Nano powders." International Journal of Mechanical and Production Engineering Research and Development 9.3 (2019): 131-142.

5. J. Rout, M. Misra, S. S. Tripathy, S. K. Nayak, and A. K. Mohanty, "The influence of fibre treatment of the performance of coir-polyester composites,” Compos. Sci. Technol., vol. 61, no. 9, pp. 1303-1310, 2001.

6. N. Saheb and J. Jog, “Natural Fiber Polymer Composites: A Review," Adv. Polym. Technol., vol. 2329, no. July, pp. 351$363,2015$.

7. N. Dhirhi et al., "Extraction Method of Flax Fibre and Its Uses,” vol. 15, no. 2, pp. 711-716, 2015.

8. K. Charlet, J. P. Jernot, S. Eve, M. Gomina, and J. Bréard, "Multi-scale morphological characterisation of flax: From the stem to the fibrils," Carbohydr. Polym., vol. 82, no. 1, pp. 54-61, 2010.

9. Oleiwi, Jawad Kadhim, Rana AfifAnaee, and SafaaHashim Radhi."Roughness wear and thermal analysis of UHMWPE Nanocomposites as Acetabular Cup in Hip Joint Replacement." International Journal of Mechanical and Production Engineering Research and Development 8.6 (2018): 855-864.

10. C. Pavithran, P. S. Mukherjee, M. Brahmakumar, and A. D. Damodaran, "Impact performance of sisal-polyester composites," J. Mater. Sci. Lett., vol. 7, no. 8, pp. 825-826, 1988.

11. G. M. A. Khan, M. Terano, M. a. Gafur, and M. S. Alam, "Studies on the mechanical properties of woven jute fabric reinforced poly(l-lactic acid) composites,” J. King Saud Univ. - Eng. Sci., pp. 1-6, 2013.

12. G. Agarwal, A. Patnaik, R. Sharma, and J. Agarwal, "Effect of stacking sequence on physical, mechanical and tribological properties of glass - carbon hybrid composites," 2014.

13. S. Biswas and A. Satapathy, "A comparative study on erosion characteristics of red mud filled bamboo - epoxy and glass epoxy composites," Mater. Des., vol. 31, no. 4, pp. 1752-1767, 2010.

14. Satyanarayana, K. R., B. Surendra Babu, and B. Ramesh Chandra. "Microstructurural characterization of 6063 aluminium alloy nano-composites." International Journal of Mechanical and Production Engineering Research and Development 8.2 (2018): 851-856.

15. S. Biswas, A. Patnaik, and R. Kaundal, "Effect of Red Mud and Copper Slag Particles on Physical and Mechanical Properties of Bamboo-Fiber-Reinforced Epoxy Composites," vol. 2012, 2012.

16. G. Agarwal, "Thermo-mechanical properties of silicon carbide-filled chopped glass fiber-reinforced epoxy composites,” p. 1, 2013.

17. A. Patnaik, A. Satapathy, and S. Biswas, "Investigations on Three-Body Abrasive Wear and Mechanical Properties of Particulate Filled Glass Epoxy Composites,” vol. 5, no. 2, pp. 37-48, 2010. 
18. Saber, D., KhAbd El-Aziz, and A. Fathy."Corrosion behavior of copper-alumina nanocomposites in different corrosive media." Int. J. Mech. Eng 5 (2016): 1-10.

19. A. Satapathy, A. Kumar Jha, S. Mantry, S. K. Singh, and A. Patnaik, "Processing and characterization of jute-epoxy composites reinforced with SiC derived from rice husk, "J. Reinf. Plast. Compos., vol. 29, no. 18, pp. 2869-2878, 2010.

20. S. Biswas, A. Satapathy, and A. Patnaik, "Effect of Ceramic Fillers on Mechanical Properties of Bamboo Fiber Reinforced Epoxy Composites : A Comparative Study,” vol. 125, pp. 1031-1034, 2010.

21. G. Kalagi and R. Patil, "Properties of Glass fiber hybridized woven Flax and Sisal fabric hybrid composites," Vol. 06, No. 1, pp. 1019-1026, 2019. 

